\title{
O PROGRAMA RESIDÊNCIA PEDAGÓGICA E A APROXIMAÇÃO COM A DOCÊNCIA EM BIOLOGIA: VIVÊNCIAS, DESAFIOS E POSSIBILIDADES
}

\author{
Leandro Passarinho Reis Júnior ${ }^{1}$ \\ http://orcid.org/0000-0001-9505-7808 \\ Maria Gorete Rodrigues Cardoso ${ }^{2}$ \\ http://orcid.org/0000-0002-0809-4748
}

RESUMO: Este texto resulta de uma pesquisa que objetivou investigar a contribuição do Programa Residência Pedagógica para aprendizagem da docência na formação inicial em Biologia. De abordagem qualitativa, recolhemos dados em documentais e nos Relatórios Finais de vinte residentes, licenciandos do Curso de Licenciatura em Ciências Biológicas do Núcleo de Belém da Universidade Federal do Pará. Os resultados apontam contribuições significativas para a aprendizagem da docência em sua dimensão pedagógica, desde o planejamento das atividades até a realização e avaliação delas, no entanto, também apontam desafios, tais como: fragilidades da formação pedagógica na universidade, ausência de formação continuada dos Preceptores e falta de infraestrutura para efetivar os projetos pedagógicos da escola.

PALAVRAS-CHAVE: Programa Residência Pedagógica; Aprendizagem da Docência; Ensino de Biologia

\section{THE PEDAGOGICAL RESIDENCE PROGRAM AND THE APPROACH TO TEACHING IN BIOLOGY: EXPERIENCES, CHALLENGES AND POSSIBILITIES}

ABSTRACT: This text is the result of a research that aimed to investigate the contribution of the Pedagogical Residency Program to teaching teaching in the initial training in Biology. With a qualitative approach, we collected data in documents and in the Final Reports of twenty residents, graduates of the Biological Sciences Degree Course at the Belém Center of the Federal University of Pará. The results point out significant contributions to teaching teaching in its pedagogical dimension, since the planning of activities until their realization and evaluation, however, also points to

\footnotetext{
${ }^{1}$ Doutor em Educação. Prof. Adjunto III do Instituto de Ciências Biológicas - ICB. Universidade Federal do Pará - UFPA. Belém, Pará, Brasil. Ipassarinho28@gmail.com

${ }^{2}$ Doutora em Educação. Prof. Adjunto II do Campus Universitário de Bragança. Universidade Federal do Pará - UFPA. Belém, Pará, Brasil. goreterc@ufpa.br
} 
challenges, such as: weaknesses in pedagogical training at the university, absence of continued training for preceptors and lack of infrastructure to carry out the school's pedagogical projects.

KEYWORDS: Pedagogical Residence Program; Teaching Learning; Biology Teaching

\section{EL PROGRAMA DE RESIDENCIA PEDAGÓGICA Y EL ENFOQUE DE LA ENSEÑANZA EN BIOLOGÍA: EXPERIENCIAS, DESAFÍOS Y POSIBILIDADES}

RESUMEN: Este texto es el resultado de una investigación que tenía como objetivo indagar en la contribución del Programa de Residencia Pedagógica a la docencia docente en la formación inicial en Biología. Con un enfoque cualitativo, recolectamos datos en documentos y en los Informes Finales de veinte residentes, egresados de la Licenciatura en Ciencias Biológicas del Núcleo de Belém de la Universidad Federal de Pará. Los resultados señalan contribuciones significativas para la enseñanza aprendizaje en su dimensión pedagógica, la planificación de las actividades hasta su realización y evaluación, sin embargo, también apunta a desafíos, como: debilidades en la formación pedagógica en la universidad, ausencia de formación continua para los preceptores y falta de infraestructura para llevar a cabo los proyectos pedagógicos de la escuela.

\section{Palavras clave: Programa de Residencia Pedagógica; Enseñanza del aprendizaje; Enseñanza de la Biología}

\section{INTRODUÇÃO}

O século XXI trouxe transformações sociais que mudaram radicalmente as relações sociais e a forma como nos comunicamos e aprendemos. Tais mudanças, por sua vez, instalaram formas de se relacionar com os outros, de ensinar e aprender, as quais impõem desafios cotidianos para a escola e, consequentemente para o professor que tem sido convocado a dinamizar suas aulas frente às constantes exigências educacionais.

Em relação à formação inicial, nos últimos anos temos acompanhado os esforços das universidades tanto em promover um currículo de formação, que antecipe cada vez mais a inserção à docência nas escolas, quanto auxilie o licenciando a usar os recursos tecnológicos como ferramenta pedagógica. Assim como Mizukami (2005), entendemos que tanto a universidade quanto a escola são agências formadoras, pois ambas promovem experiências significativas para o tornar-se professor/a. 
Na mesma medida, políticas públicas têm sido implementadas para estimular a participação dos licenciandos nos contextos escolares e, de alguma forma, suprir a carência de professores nas áreas das Ciências da Natureza, dentre elas, o Programa Residência Pedagógica, criado em 2018 e integrado à Política Nacional de Formação de Professores. O referido programa "tem como objetivo, conforme seu primeiro edital, induzir o a perfeiçoamento da formação prática nos cursos de licenciatura, promovendo a imersão do licenciando na escola de Educação Básica, a partir da segunda metade do Curso (BRASIL, 2018)".

Assim, nossa investigação se dá no contexto de uma universidade pública, que realizou o Programa Residência Pedagógica - Núcleo Biologia/Belém numa escola-campo de Ensino Médio integral da Educação Básica, no período de agosto de 2018 a janeiro de 2020 na Região Metropolitana de Belém/PA.

Diante do exposto, o objetivo da pesquisa foi investigar a contribuição do Programa Residência Pedagógica para a aprendizagem e experimentação da docência de 20 (vinte) licenciandos em Ciências Biológicas da Universidade Federal do Pará (UFPA). Fomos conduzidos pela seguinte inquietação: Como o Programa Residência Pedagógica contribuiu para a aprendizagem da docência dos futuros Biólogos Educadores?

Neste estudo, apresentamos um breve histórico do Curso de Ciências Biológicas no país e na Universidade Federal do Pará, trazemos uma reflexão sobre a aprendizagem da docência em conexão com a formação de professores em Biologia e a emergência do Programa Residência Pedagógica. Em seguida, descrevemos o percurso metodológico da pesquisa e, por fim, as análises dos impactos do referido programa na formação inicial dos participantes da pesquisa.

\section{BREVE HISTÓRICO DO CURSO DE BIOLOGIA NO BRASIL E NA UFPA}

Não há como imaginarmos o mundo de hoje, com todos os avanços científicos e tecnológicos, sem o ensino de Ciências e Biologia, porém, de acordo com Krasilchik (1987), os respectivos componentes curriculares só foram incorporados ao currículo obrigatório nos anos finais do antigo curso Ginasial, por meio da Lei de Diretrizes e Bases da Educação no 4.024/61, no governo do então Presidente João Goulart. Em 1971, a Lei de Diretrizes e Bases no 5692/71 tornou obrigatório o ensino de Ciências Físicas e Biológicas no antigo 1ํgrau, hoje Ensino Fundamental.

Todavia, os esforços em formar profissionais em Ciências Biológicas surgiram muito antes, especificamente no ano de 1934, na Faculdade de Fi- 
losofia da Universidade de São Paulo (USP), com a denominação de História Natural. Segundo Tomita (1990), tais iniciativas emergiram de acontecimentos marcantes no país, como a Reforma de Sampaio Dória, em 1920, e o Manifesto dos Pioneiros da Escola Nova, movimentos estes que impulsionaram o espírito de experiências acadêmicas e científicas no Brasil.

Vale ressaltar que logo após a USP, a Universidade do Brasil (atual Universidade Federal do Rio de Janeiro - UFRJ) também criou o Curso de História Natural, destinado à formação de professores de Ciências Físicas e Biológicas. Apenas após quase três décadas surge o desdobramento do Curso de História Natural em dois cursos de graduação: Bacharelado em Geologia e Licenciatura em Ciências Biológicas, devido à expansão da profissão de Geólogo no país.

Em seguida, várias instituições públicas de Ensino Superior também abarcaram tal empreitada. Segundo Haddad (2006), as primeiras instituições brasileiras a ofertarem o Curso de História Natural (e posteriormente Licenciatura em Ciências Biológicas) foram as seguintes: Universidade de São Paulo (1934); Universidade Federal Rural do Rio de Janeiro (1934); Universidade Federal do Paraná, Universidade Federal de Pernambuco e Universidade Federal da Bahia (1946); Universidade Federal de Minas Gerais (1949); Universidade Federal do Rio Grande do Sul (1942); por fim, a Universidade Federal do Pará (1957).

Na Universidade Federal do Pará (UFPA), o curso de Licenciatura Plena em Ciências Biológicas iniciou no ano de 1970, com a criação do Centro de Ciências Biológicas (CCB), atual Instituto de Ciências Biológicas (ICB), que teve como primeiro diretor e fundador o professor Manuel Ayres. Sua criação buscou dar conta da necessidade de se formar professores para atuar na área de Ciências Biológicas, em virtude da vocação de seu fundador para a formação de recursos humanos para o ensino e pesquisa em sua própria área de atuação (UFPA, 2019).

O Curso de Ciências Biológicas (Bacharelado e Licenciatura) da UFPA oferta anualmente 80 vagas para modalidade Licenciatura e 40 vagas para a modalidade Bacharelado, formando profissionais capacitados para atuação na Amazônia. Hoje, é a segunda maior licenciatura da UFPA em número de alunos matriculados e formados, habilitando uma grande população de professores em Ciências e Biologia, capacitados para atuar no ensino e pesquisa, em ambientes formais e não formais de educação. 


\section{A SUPERAÇÃO DA RACIONALIDADE TÉCNICA NA FORMAÇÃO DE PROFESSORES DE BIOLOGIA E A APRENDIZAGEM DA DOCÊNCIA}

Sabemos que as reformulações das Diretrizes Curriculares Nacionais dos Cursos de formação de professores foram consideravelmente influenciadas pelos postulados de Donald Schön no início deste século. Isso não foi diferente no Curso de Licenciatura em Ciências Biológicas da Universidade Federal do Pará.

Naquele momento, criticava-se veemente o currículo de formação de professores organizado com base no modelo $3+1$ ( 3 anos de teoria mais 1 ano de Prática de Ensino), o qual priorizava a racionalidade técnica como pressuposto formativo. Neste modelo, o professor era concebido como um técnico especialista que deveria a plicar, com rigor, as regras advindas do conhecimento científico e, portanto, precisava dominar as teorias e conteúdos para depois aplicá-los na prática educacional.

Todavia, a realidade educacional mostrava que a centralidade técnica no domínio de conteúdo fragilizava o campo didático, isto é, não dava subsídios para que o professor dominasse e se saísse bem na "Arte de ensinar". Ao contrário, muitos problemas de ensino-aprendizagem estavam centrados exatamente na dificuldade de professores, especialmente na área das Ciências da Natureza, conseguirem realizar a transposição didática dos conteúdos e conhecimentos biológicos, especialmente da formação do Biólogo, arduamente trabalhados na formação inicial nas universidades.

Certamente, estávamos diante de um dilema: garantir uma sólida formação dos conhecimentos biológicos, mas, promover também uma formação pedagógica capaz de subsidiar a prática docente dos futuros professores, contribuindo assim para a aprendizagem em Biologia. Nesse sentido, os esforços das reformulações de Cursos de licenciatura foram significativos para propor um currículo de formação que conseguisse antecipar cada vez mais a inserção dos licenciandos na escola básica, a sua convivência com a docência e, consequentemente, a sua aprendizagem no ensino de Biologia.

Especialmente no Curso de Licenciatura em Ciências Biológicas da UFPA, as disciplinas pedagógicas e os Estágios foram antecipados para o início da formação, tentando garantir tanto a identificação com o campo docente quanto sua vivência e experimentação prática, contribuindo, assim, para a formação do Biólogo Educador.

Tais mudanças foram alicerçadas também pelos pressupostos de Nóvoa (2013), cuja preocupação volta-se para a importância do professor nas 
mudanças sociais. Para o autor, a formação de professores é um continuum, que precisam de investimentos bem delineados para então alcançarmos os avanços sociais.

Em seus ensinamentos, ele nos alerta que "é no coração da profissão, no ensino e no trabalho escolar que devemos centrar nosso esforço de renovação da formação de professores" (NÓVOA, 2013, p. 204). Não existe para o autor, mudança social que não passe pela mudança educacional e pelos investimentos na formação de professores, mas para que isso ocorra, é necessário percorrer quatro caminhos: 1) uma formação de dentro a partir da profissão professor; 2) uma valorização do conhecimento docente, no qual o ensino seja considerado como um campo de criação, colaboração e intervenção de práticas educativas; 3) a criação de uma realidade organizacional, em que os professores possam criar seus coletivos de colaboração e valorização profissional; 4) o reforço do espaço público de educação, no qual a escola ocupe seu lugar de destaque na sociedade. Desta forma, segundo o autor, a educação e a escola conseguirão cumprir seu papel sócio-político na sociedade inclusiva e democrática.

Contudo, a influência decisiva na transformação curricular de formação de professores de Biologia foi o ensino reflexivo de Donald Schön. Embasado na Pedagogia Ativa de John Dewey, que enfatiza a aprendizagem por meio das experiências e do fazer, Schön nos ensina que o aprendiz tem que enxergar por si próprio e à sua maneira, as relações entre meios e métodos empregados com resultados atingidos. Em outras palavras, o discente deve fazer, sentir, pensar e viver as experiências educativas, para que então seja capaz de aprender os conceitos, conhecimentos e saberes.

Temos aqui uma epistemologia da prática, a qual se apoia nos conceitos de conhecimentos da ação e de reflexão na ação, isto é, para aprender a ser professor, é preciso vivenciar a docência nos espaços escolares, construir saberes sobre ela e refletir sobre novos conhecimentos e ações para ela. Esse movimento mostrou-se interessante, pois a prática coloca-se no mesmo patamar que os conhecimentos teóricos, complementando-se na formação do futuro professor.

Estava aí o elemento que faltava para a formação em Biologia, pois os conteúdos tradicionalmente garantiam o saber das Ciências Biológicas, porém fragilizavam, sobremaneira, o saber-fazer, ou seja, a instrumentalização didático-pedagógica desse saber na atuação docente. Assim, tínhamos uma licenciatura presa ao bacharelado, que pouco formava o futuro professor de Biologia dada a sua densidade técnica curricular. 
Schön (2000) nos ensinou que o conhecimento na ação é o componente que está diretamente relacionado ao saber-fazer, é espontâneo, implícito e surge na ação, ou seja, um conhecimento tácito. Sendo assim, a reflexão se revela a partir de situações inesperadas produzidas pela ação, logo, nem sempre o conhecimento na ação é suficiente. São três tipos distintos de reflexão: a reflexão sobre a ação, a reflexão na ação e a reflexão sobre a reflexão na ação. A reflexão sobre a ação consiste em pensarmos retrospectivamente sobre o que fizemos, almejando descobrir como nosso ato de conhecer-na-ação pode ter contribuído para um resultado inesperado. Já a reflexão-na-ação consiste em refletirmos no meio da ação, sem interrompê-la. Nosso pensamento nos conduz a dar nova forma ao que estamos fazendo e no momento em que estamos fazendo, possibilitando interferir na situação em desenvolvimento.

Porém, Mizukami (2005) nos chama a atenção para que não façamos uma apologia da prática, pois ela sozinha também não conseguirá "formar" o professor para a escola atual. Segundo a autora, também precisamos atentar para o envolvimento de outros aspectos que, juntamente com a prática, auxiliarão a aprendizagem da docência, tais como:

- conhecimento do conteúdo específico, compreendido como eixo articulador da base de conhecimento para a docência e para promoção de processos de raciocínio pedagógicos ricos e flexíveis, possibilitando a compreensão das inter-relações entre os conteúdos dos diferentes componentes curriculares e os contextos de aprendizagem dos alunos e dos professores, bem como das especificidades das diferentes séries e níveis de escolarização;

- conhecimento de contextos formativos escolares, como funcionam as escolas (dinâmicas, tempos, espaços, condições objetivas de trabalho do professor, organização do trabalho escolar, alunos etc.);

- conhecimento de processos de aprendizagem da docência, com o intuito de promovê-los adequadamente em diferentes contextos. Implica reconhecer e explorar concepções/teorias pessoais dos professores/futuros professores, seja no sentido de reafirmar tais concepções ou de alterá-las;

- conhecimento historicamente contextualizado e fundamentado de políticas públicas educacionais e das teorias que as embasam, de forma a serem evitadas distorções e/ou simplificações indevidas quando transpostas para a sala de aula, como, por exemplo, o trabalho exclusivo com a oralidade em detrimento da escrita, o privilégio de alguns componentes curriculares, exploração equivocada dos erros, contribuições, concepções prévias em nome de referências teóricas compreendidas de forma simplista e fragmentadas;

- especificidade do conhecimento pedagógico do conteúdo (único 
tipo de conhecimento do qual o formador é realmente protagonista), abarca o conhecimento tanto sobre a promoção de processos de aprendizagem da docência quanto conhecimento sobre a prática profissional como eixo de processos formativos.

Portanto, ao aliarmos as vivências práticas da formação aos aspectos acima citados, sem sombra de dúvida, avançaremos para uma aprendizagem da docência que poderá dar mais confiança e credibilidade para o futuro professor de Biologia, que ao compreender a complexidade e continuidade do seu fazer buscará formas de reinventar-se.

\section{BREVE APRESENTAÇÃO DO PROGRAMA INSTITUCIONAL RESIDÊNCIA PEDA- GÓGICA (PRP)}

O PRP é um programa vinculado à Coordenação de Aperfeiçoamento de Pessoal de Nível Superior (CAPES). Foi criado no bojo de ações para o fortalecimento da Política Nacional de Professores liderada pela CAPES desde 2009, com o intuito de fortalecer o aperfeiçoamento da formação prática nos cursos de licenciatura.

O foco do programa é elevação da qualidade da educação do país, com o fortalecimento da prática docente de licenciandos inseridos no cotidiano da rede pública de Educação Básica, com o objetivo de vivenciar experiências de ser professor. Como a Portaria no 38 de 28/02/2018 previu a participação de todas as áreas de conhecimento, dentre elas a Biologia, fomos inseridos com êxito pela Universidade Federal do Pará.

Assim, o Núcleo Biologia de Belém foi composto por 1 (um) Coordenador, 3 (Três) Preceptoras e 20 (vinte) Residentes que atuaram numa Escola Pública de Ensino Médio Integral na região metropolitana de Belém/PA. Todos os integrantes do PRP, coordenadores, Preceptores e Residentes receberam bolsas de estímulo à participação.

Por meio do programa, os licenciandos puderam envolver-se na rotina das escolas públicas, que abrangem o planejamento pedagógico, questões socioculturais dos alunos, relações interpessoais, questões administrativas até a prática de ensino em sala de aula no período de um ano letivo escolar. Nesse sentido, o PRP aproximou mais a universidade da escola pública, promovendo maior diálogo e troca de aprendizagens no tange ao ensino, pesquisa e extensão. 


\section{PERCURSO METODOLÓGICO DA PESQUISA}

O estudo foi ancorado na abordagem qualitativa, focalizando na coleta de dados do Relatório Final de Avaliação dos Residentes, visando obter a percepção dos envolvidos acerca do impacto de sua participação no Programa Residência Pedagógica para aprendizagem docente como futuro professor de Biologia.

Recolhemos no final do ano de 2019, os Relatórios Finais de 20 (vinte) Residentes do Programa Residência Pedagógica - Núcleo Biologia/Belém, regularmente matriculados no Curso de Licenciatura em Ciências Biológicas da UFPA. Vale ressaltar que participaram da pesquisa 10 homens e 10 mulheres, na faixa etária que varia de 20 a 42 anos.

Para resguardar a identidade dos participantes do estudo, eles foram identificados pelas iniciais de seus nomes e autorizaram por escrito a utilização dos dados dos relatórios.

Por questões éticas optamos por criar pseudônimos para os Residentes, homenageando as flores da botânica brasileira: Amor-perfeito (Viola $x$ wittrockiana), Amarílis (Amaryllis), Antúrio (Anthurium andraeanum), Azaléia (Rhododendron simsii), Begônia (Begonia semperflorens), Bromélia (Alcantarea imperialis), Camélia (Camellia japonica), Copo-de-leite (Zantedeschia aetiopica), Cravo (Dianthus caryophyllus), Girassol (Helianthus annuus), Hibisco (Hibiscus rosa-sinensis), Jasmin (Jasminum), Lírio (Lilium pumilum), Lótus (Nelumbo nucifera), Margarida (Leucanthemum vulgare), Narciso (Narcissus spp.), Orquídea (Orchidaceae), Rosa (Rosa x grandiflora), Tulipa (Tulipa sp.) e Violeta (Saintpaulia ionantha).

Processos formativos docentes vêm sendo investigados ao longo dos anos por pesquisadores como Krasilchik $(1987,2008)$, Marandino $(2000,2001$, 2005) e Chaves (2000, 2013), dentre outros, enfatizando a complexidade da formação docente, especialmente, em cursos clássicos científicos como as Ciências Biológicas.

Levando em conta tais estudos e entendendo que o ensino de Biologia também tem como objetivo promover experiências de como a vida pode ser observada, analisada e refletida em diversos espaços e contextos humanos e sociais, a proposta do PRP veio somar os esforços de promover uma formação de professores de Biologia repleta de reflexões e ferramentas didáticas para sua consolidação.

Os dados recolhidos foram analisados à luz da Análise de Conteúdo, que trata de um conjunto de técnicas de análise das comunicações, que utiliza 
procedimentos sistemáticos e objetivos de descrição do conteúdo das mensagens (BARDIN, 2006). Da mesma forma, os dados obtidos foram sistematizadas em 3 (três) categorias de análise, que convergiram com os objetivos da pesquisa: 1) Ambientação na Escola; 2) Contribuições do PRP para Aprendizagem da Docência; e 3) Dificuldades encontradas nesse processo formativo.

\section{VIVENCIANDO A APRENDIZAGEM DA DOCÊNCIA EM BIOLOGIA}

A partir do embasamento teórico que sustenta este estudo, bem como orientados pelos objetivos da pesquisa, delineamos as categorias de análise. É válido esclarecer que diante do volume de dados, optamos por selecionar aqueles que focavam mais os objetivos da pesquisa, os que mais expressavam as contribuições do Programa Residência Pedagógica para aprendizagem da docência.

\section{1) Ambientação na Escola}

Tendo a compreensão que a Educação e o Ensino são práticas sociais, repletas de possibilidades de interações humanas e aprendizagens, os Residentes apontaram algumas atividades desenvolvidas no contexto escolar, tais como: ambientação e conhecimento da escola; Regência; Participação dos Projetos Pedagógicos da Escola; Participação em eventos acadêmicos e reativação do Laboratório de Biologia da Escola.

Como a ambientação consistiu o primeiro momento de inserção na escola, este período durou 3 (três) meses, para que fossemos conhecendo, participando e planejando as ações que poderiam ser realizadas no contexto escolar. Vale ressaltar que o fato de nos inserirmos numa escola pública integral abriu um leque de possibilidades de atuação. Para melhor condução do Programa in loco, o grupo foi subdivido em 3 (três) equipes vinculadas a cada Preceptor/a de Biologia.

Com isso também foi possível participar ativamente do Planejamento Pedagógico da Escola e conhecer sua atuação nas diversas áreas do conhecimento, promovendo inclusive interlocução para atividades interdisciplinares.

Canário (1997) nos ensina que a produção e a transformação das práticas profissionais estão intrinsecamente atreladas ao processo de socialização profissional, vivenciado nos contextos de trabalho, no qual ocorre uma dinâmica formativa e um processo de construção de identidade. Nessa perspectiva, a formação do futuro docente necessita ocorrer no interior da escola 
e não somente no interior da Universidade.

Em seguida foram planejadas e realizadas as Regências, que é uma etapa fundamental da aprendizagem da docência, pois nela aplicam-se os saberes da docência que vão desde o planejamento de ensino até a ação didática. Sobre essas experiências, os licenciandos mergulharam no conteúdo curricular de Biologia, com aulas de Corpo Humano, Ecologia, Zoologia, Botânica, Genética, Evolução, enfim os conteúdos exigidos para o Exame Nacional do Ensino Médio (ENEM).

Nesse momento, a criatividade inspirou os aprendizes docentes para elaboração de materiais didáticos, jogos, palestras, debate de filmes e documentários etc. Lá no chão da escola, eles perceberam e se convenceram do quanto a Biologia se faz presente no cotidiano de todos nós e como os problemas do mundo também podem ser entendidos pela visão do conhecimento biológico.

Em relação aos Projetos já desenvolvidos na escola, foi possível a inserção no Projeto Biologia Cidadã, o qual promoveu mensalmente palestras e roda de conversa acerca de problemas ambientais e sociais de utilidade pública, estimulando os alunos da escola a se envolverem na divulgação dos conhecimentos científicos e orientações para saúde e bem estar. Já a participação em eventos científicos ocorreu por meio do 2 o Seminário Integrado de Ensino, Pesquisa e Extensão da UFPA, com a aprovação de 5 (cinco) resumos expandidos e 1 (uma) comunicação oral, com a participação de Coordenação do Núcleo Biologia de Belém, Preceptores/as e Residentes.

Por fim, cabe salientar o empenho dos envolvidos no PRP para a reativação do Laboratório de Biologia da escola, que se encontrava inativo e abandonado sem ofertar aulas práticas experimentais para os alunos. Conseguimos pela UFPA a doação de 1 (um) microscópio lupa para as aulas de microscopia e microbiologia, contribuindo para que a observação e análises práticas de materiais microbiológicos também fizessem parte da rotina escolar.

Acerca disso, Berezuk e Inada (2010) enfatizam que as aulas experimentais são essenciais para que os alunos tenham um aprendizado eficiente e estruturado em diversos cursos, principalmente na área das Ciências e Biologia, pois somente neste tipo de aula os alunos utilizam os materiais, manuseiam equipamentos, presenciam fenômenos e organismos que podem ser observados a olho nu ou com a ajuda de microscópios. Além disso, nas aulas práticas, os alunos avaliam resultados, testam experimentos, bem como exercitam o raciocínio e solucionam problemas, sendo estimulados ao desafio.

Corroboramos com a ideia de que as aulas práticas experimentais 
possibilitam ao aluno fazer Ciência, desde a sua problematização evocada pela criatividade humana, passando pelas etapas de execução de cada experimento até as análises dos resultados obtidos que, por sua vez, levantam outras problematizações.

Enfim, trata-se de um exercício necessário para o ensino-aprendizagem em Biologia, haja vista que os processos biológicos podem e devem ser trabalhados na perspectiva teórico-prática, possibilitando aos aprendizes exercitarem e entenderem que o fazer Ciência também faz parte da construção e desenvolvimento de uma sociedade.

\section{2) Contribuições do PRP para aprendizagem da docência}

Em unanimidade, os relatórios apontaram contribuições significativas para a aprendizagem da docência em Biologia, conforme os relatos a seguir:

O programa contribuiu de forma significativa para a minha formação profissional e acadêmica, as experiências vividas vão servir de base para moldar o profissional que quero ser (Tulipa, 2020).

O projeto foi fundamental para minha aproximação e identificação com a docência em Biologia, onde pude exercitar, ensinar e aprender com os alunos (Bromélia, 2020).

O projeto foi importantíssimo para minha identificação como professora de biologia (Copo-de-leite, 2020).

Acredito que o Programa Residência Pedagógica é um divisor de águas na formação dos futuros licenciados. Tive a sorte de ter uma preceptora muito participativa e bastante exigente de modo que me deu liberdade e autonomia docente. Sempre prestativa no tocante a exigir mais e orientar na melhoria de nossa produção pedagógica. Termino este programa de modo satisfatório e feliz, pois pude aproveitar cada oportunidade que me foi dada e deste modo crescer profissionalmente (Rosa, 2020).

Contribuiu trazendo a realidade de ser docente, uma vez que as disciplinas de estágio na universidade ficam longe do esperado (Antúrio, 2020).

Tulipa destaca o papel das experiências e vivências didáticas na escola para formação docente, enfatizando inclusive o quão importante elas serão para a carreira docente, aquele amálgama que Tardif (2002) denominou de Saberes 
Docentes. Para ele, o saber docente é um "saber plural, formado de diversos saberes provenientes das instituições de formação, da formação profissional, dos currículos e da prática cotidiana (experienciais)" (TARDIF, 2002, p. 54).

Mesmo entendo que os saberes são relacionais e intrínsecos, Tardif chama a atenção para a posição de destaque ocupada pelos saberes experienciais em relação aos demais saberes dos professores. Segundo o autor, no caso da profissão docente, esta precisa ser entendida como uma aprendizagem exercida no cotidiano, por meio do qual os professores vivem situações concretas que requerem habilidade, interpretação e improvisação durante o processo de ensino-aprendizagem, para avaliarem e reinterpretarem outras técnicas, metodologias e ações didáticas.

Em outras palavras, diferentemente de outras profissões que precisam primeiramente de uma vasta base teórica para subsidiar a prática profissional, na docência, a teoria precisa ser observada, analisada e refletida conjuntamente com a prática, mobilizando assim os saberes da docência e fortalecendo a aprendizagem docente. No caso da Biologia, oriunda de uma tradição forte dos conhecimentos técnicos e com vocação para a pesquisa, esta precisa se aproximar das atividades de ensino, tendo em vista que no Ensino Médio há uma realidade específica de aprendizes que precisam conectar os conhecimentos biológicos à sua vida e aos seus projetos de futuro.

Nesse sentido, o relato de Bromélia realça que atrelada à discussão dos saberes docentes está o debate acerca da identidade docente. Para autores como Nóvoa (1997), a identidade docente é condição necessária para sua profissionalização. Ele defende que identidade não é um lugar ou produto adquirido, logo, "é um lugar de lutas e conflitos, é um espaço de construção de maneiras de ser e estar na profissão" (NÓVOA, 1997, p. 47).

Ao reportarmos tal discussão para nossas lentes, a nossa práxis enquanto formador de professores mostra-nos que a maioria dos licenciandos em Ciências Biológicas não se vê como professor de Biologia e sim como Biólogos, colocando por vezes o magistério como uma condição inferior, se aproximando das oportunidades de pesquisa e se afastando das experiências docentes.

Diversos autores como Alcântara e Souza (2017), Rocha (2013), Vasconcelos e Lima (2010) se ocuparam de investigar a construção de uma identidade docente dos alunos de licenciatura em Ciências Biológicas. Dentre esses, destacamos o estudo realizado com 85 dos 195 egressos do curso de Licenciatura em Ciências Biológicas em uma universidade pública do estado de Minas Gerais, o qual identificou que apenas 30\% dos alunos pesquisados haviam feito opção prévia pelo magistério quando optaram pela modalidade 
licenciatura ao ingressarem no curso (ROCHA, 2013).

Tais apontamentos se somam ao relato de Rosa, que além de enaltecer o ganho profissional que o PRP Ihe proporcionou, também destacou o papel da Preceptora que Ihe auxiliou nesse processo, confiando-Ihe atenção, disponibilidade e autonomia para que pudesse experimentar e vivenciar o ser professora de Biologia na escola, tarefa imprescindível para a formação docente.

Tendo em vista que toda ação humana supõe uma mediação, Vygotsky (1999) nos chamou atenção para o caráter de reciprocidade que ocorre em qualquer ação educativa e que dela dependerá as possibilidades de conhecer e aprender. No caso da aprendizagem docente, é importante que essa tarefa seja mediada por professores em serviço que auxiliem os licenciandos a desenvolverem sua ação educativa, mediando sua formação.

Em se tratando de licenciandos em Ciências Biológicas, esses em sua maioria entram no curso com pouca clareza de sua atuação docente. Durante sua formação, experimentam poucas possibilidades dessa atuação, por isso entendemos a necessidade de haver aproximação e interlocução com a escola, com o saber e fazer docente.

Tal debate ancora-se ao relato de Antúrio, o qual aponta as fragilidades da formação pedagógica no Curso de Licenciatura em Ciências Biológicas, destacando a disciplina Estágio como um espaço que poderia possibilitar também mais aprendizagens da docência. No caso do Curso de Licenciatura em Ciências Biológicas do Instituto de Ciências Biológicas da Universidade Federal do Pará, ressaltamos que este vem se reformulando há cerca de dez anos na tentativa de minimizar essas fraturas da base pedagógica, porém ainda há o desafio de romper com essa lógica obsoleta de separação do conhecimento biológico e conhecimento pedagógico, o que dificulta, a nosso ver, a aprendizagem da docência em Biologia.

Selles e Ferreira (2008), ao problematizarem a formação docente no Brasil, mostram-nos como a formação profissional encontra-se amarrada na apropriação de conhecimentos aprendidos em contextos acadêmicos não diretamente transferíveis para o contexto escolar, ocasionando o distanciamento do cotidiano escolar. Eles evidenciam o quanto nos currículos dos cursos de licenciatura, a educação passa a ser considerada uma ciência aplicada, fundamentando-se na concepção epistemológica da racionalidade técnica.

Daí o grande desafio que temos na universidade, transformar de fato o nosso curso de licenciatura em Ciências Biológicas em formação de professores, possibilitando, ao aluno desde as primeiras atividades curriculares, experiências teórico-práticas em espaços educativos, mostrando-Ihes como 
as Ciências e a Biologia são necessárias para entender o mundo a nossa volta. Sabemos que não se trata de uma tarefa simples, porém o PRP soma esforços para o enriquecimento da aprendizagem docente na formação inicial de futuros professores de Ciências e Biologia.

3) Dificuldades encontradas nesse processo formativo

Apesar da gama de possibilidades de aprendizagem da docência enfatizadas nos excertos anteriores, como todo processo pedagógico também ocorreram fragilidades, traduzidas aqui nos relatos de alguns Residentes.

A esse respeito Amor-perfeito destaca:

[...] o principal desafio veio no início do processo: estar em sala de aula, assumir o papel de professor diante dos alunos. Após esse primeiro momento, veio o segundo desafio, que descobri ser o que irá me acompanhar por toda a profissão: vencer o mundo do método tradicional de ensino, as aulas expositivas e cansativas, os alunos com sono, sem compreender o que estão aprendendo (Amor Perfeito, 2020).

Sobre isso, Krasilchik (2008, p. 11) destaca que:

[...] no estágio atual do ensino brasileiro, a configuração do currículo escolar dos ensinos médio e fundamental deve ser objeto de intensos debates, para que a escola possa desempenhar adequadamente seu papel na formação de cidadãos. Como parte desse processo, a biologia pode ser uma das disciplinas mais relevantes e merecedoras da atenção dos alunos, ou uma disciplina mais insignificante e pouco atraente, dependendo do que for ensinado e de como isso for feito.

Vale ressaltar que embora Biologia e Ciências sejam disciplinas interessantes por abordarem a vida sob múltiplas formas, percebe-se que as mesmas poderiam estimular ainda mais a curiosidade e experimentação dos alunos na escola. Cremos que tal problemática deve-se provavelmente à forma como são apresentadas aos alunos, geralmente com excesso de conteúdos teóricos e nomenclaturas complexas, que distanciam os saberes biológicos do cotidiano e da vida dos aprendizes. Nota-se, portanto que dependendo de sua condução, elas podem se tornar algo mecânico, mas com o auxílio de estratégias e recursos didático-pedagógicos como jogos, filmes, documentários e 
aulas práticas, tais disciplinas podem propiciar um conhecimento interessante e totalmente entrelaçado com a vida.

Narciso complementa que:

[...] acho que por ser um programa novo, a maior dificuldade foi associar qual seria nossa função real na escola e o que nos diferenciaria de um estagiário comum. Minhas expectativas com o Residência foram maiores que foi vivido na escola, o método tradicional ainda é uma barreira forte a ser trabalhada pela escola, e nós como residentes não temos como fazê-la sozinhos se o estado não trabalha de forma eficaz. (Narciso, 2020)

A falta de infraestrutura também apareceu em quase todos os relatórios, conforme enfatiza Girassol (2020): "mesmo com a motivação tanto nossa como residentes quanto dos alunos, infelizmente a escola encontra-se com problemas físicos, com ar condicionado queimado, o que interferiu nas aulas, infelizmente".

Em um estudo realizado por Monteiro e Silva (2015) sobre a influência da estrutura escolar no ensino de Geografia, observou-se que a infraestrutura física da escola, principalmente a sala de aula, é um espaço que precisa ser estruturado para que o processo ensino-aprendizagem ocorra satisfatoriamente, pois é onde acontecem as principais relações do ensinar e do aprender. "Se não há uma boa sala de aula, que ofereça as mínimas condições de comodidade, tanto para o aluno quanto para o professor, esse processo será defasado" (MONTEIRO; SILVA, 2015, p. 28).

Não tem como negar a influência da infraestrutura física e humana na aprendizagem escolar, sobretudo, em disciplinas teórico-práticas como a Biologia. Acreditamos que para aprender, além do aluno estar motivado, ele também necessita de um espaço acolhedor, confortável, que lhe possibilite conhecer e aprender os conhecimentos biológicos. Logo, nota-se o quanto a escola tem sido esquecida nesse aspecto, o que demonstra, infelizmente, pouca atenção do poder público para com os investimentos em educação em nosso estado.

\section{CONSIDERAÇÕES FINAIS}

Decerto, o Programa Residência Pedagógica fincou sua contribuição para a formação de professores no Brasil, inclusive para professores de Biologia, visto que desde seu início possibilitou-lhes adentrar no espaço escolar, 
vivenciar e aprender a ser professor.

Consideramos um passo importante para a consolidação da relação teoria e prática, tão discutida e tão almejada nos espaços institucionais de formação de professores. Todavia, à medida que tal iniciativa se coloca como um campo fértil para as experiências docentes, percebemos que ela evidencia os percalços da escola pública que afetam diretamente a aprendizagem.

Um fator marcante consiste na falta de infraestrutura, que denuncia o descaso com a Educação, em uma escola quase centenária e referência em educação no município de Belém. Constatamos infiltrações, salas de aula com pouca climatização e iluminação, algo complicado em numa região de clima equatorial quente-úmido.

Com o PRP, reativamos o Laboratório de Biologia, que se tornou um centro de vivências e aprendizagens únicas, pois permitiu aos Preceptores, Residentes e alunos da escolar conhecer uma outra Biologia, uma Ciência prática, interessante e contextualizada, despertando ou reafirmando o desejo de ser professor de Biologia e contribuir para a vida de cada aluno da escola.

Como se tratou da primeira versão do PRP, percebemos que também houve percalços no processo de ambientação e regência, como a dificuldade de conciliar os horários das atividades na universidade com o compromisso na escola, ocorrências que não apagaram o brilho da atuação docente, do ambientar-se na escola e levar mais vida e alegria para ela, de vivenciar as etapas de uma carreira docente (desde o planejamento de aulas até sua realização) e das recompensas dos sorrisos e afetos a cada aula de Biologia.

Outro fator que merece atenção diz respeito à fragilidade da formação pedagógica no Curso de Ciências Biológicas, uma retórica que apareceu nos relatos dos alunos, que contribui, a nosso ver, para o afastamento da docência em Biologia. Embora tenhamos avançando numa proposta curricular que antecipa as discussões sobre a educação e a docência, tais discussões só ganham sentido a partir de uma prática reflexiva na escola e para a escola. Nesse sentido, uma iniciativa como o PRP além de enaltecer a docência num Curso de Biologia que busca seu lugar na docência, bem como promove uma vivência mais intensa e colabora sobremaneira para a formação da identidade docente em Biologia, por esse motivo, defendemos a permanência dos editais de ensino que estimulem a valorização da docência, como o PRP.

Por fim, os relatos dos alunos demonstram a gama de riquezas que o Programa proporciona, especialmente, na realidade de um curso de licenciatura em Ciências Biológicas, que ainda luta para colocar a docência em um lugar de destaque como a pesquisa. Com isso, reafirmamos nosso compromisso com as 
iniciativas de ensino que aproximem cada vez mais a universidade da escola, mobilizando o desejo de uma educação mais crítica, contextual e democrática.

\section{Referências}

ALCANTARA, M. A. R.; SOUZA, A. C. G. de A. Formação inicial de professores: perfil dos alunos ingressantes em ciências biológicas. Revista Profissão Docente 16.34, 2017. Disponível Em: http://www.periodicos.uffs.edu.br/ Texto\%20 do\%20artigo-28039-2-10-20180621\%20(3).pdf Acessado em 10 jun 2020

BARDIN, L. Análise de conteúdo. 11 ed. São Paulo: EDIÇÕES 70, 2006.

BEREZUK, P.A.; INADA, P. Avaliação dos laboratórios de ciências e biologia das escolas públicas e particulares de Maringá, Estado do Paraná. Acta Scientiarum. Human and Social Sciences, v. 32, n. 2, p. 207-215, 2010. https://doi. org/10.4025/actascihumansoc.v32i2.6895

BRASIL. Edital Capes no 06/2018 - Programa Residência Pedagógica. Brasília: CAPES, 2018. Disponível em: https://capes.gov.br/images/stories/download/ editais/01032018-Edital-6-2018-Residencia-pedagogica.pdf Acessado em 01 mai 2020.

CANÁRIO, R. A escola: o lugar onde os professores aprendem. Aveiro: Universidade de Aveiro, 1997.

CHAVES, S. A construção coletiva de uma prática de formação de professores de ciências: tensões entre o pensar e o agir. Tese (Doutorado em Educação). Faculdade de Educação, Universidade Estadual de Campinas, 2000.

CHAVES, S. A. Reencantar a ciência, reinventar a docência. Rio de Janeiro: Lf, 2013

FLICK, U. Qualidade na pesquisa qualitativa. Coleção Pesquisa Qualitativa (Coordenação de Uwe Flick). Porto Alegre: Bookman, Artmed, 2009.

HADDAD, A.E. (org.). A trajetória dos cursos de graduação na área da saúde: 1991-2004. Brasília: Instituto Nacional de Estudos e Pesquisas Educacionais Anísio Teixeira, 2006.

KRASILCHIK, M. O professor e o currículo das ciências. São Paulo: Editora Edusp, 1987.

KRASILCHIK, M. Prática de ensino de biologia. 4 ed. São Paulo: Editora Edusp, 2008. 
MARANDINO, M. Museu e escola: parceiros na educação científica do Cidadão. In: CANDAU, V. M. F (Org.). Reinventar a escola. Petrópolis: Vozes, 2000.

CANDAU, V. M. F. Conhecimento Biológico em Exposições de Museus de Ciências: análise do processo de produção do discurso expositivo. Tese (Doutorado em Educação). Faculdade de Educação, Universidade de São Paulo, 2001.

CANDAU, V. M. F. A pesquisa educacional e a produção de saberes nos museus de ciência. Revista História, Ciências, Saúde, v. 12, p. 161-81, 2005.

MIZUKAMI, M.G.N. Aprendizagem da docência: professores formadores. Revista E-Curriculum, v. 1, n. 1, 2005. Disponível em: https://revistas.pucsp.br/ curriculum/article/view/3106/2046 Acesso em: 12 jun. 2020.

MONTEIRO, J. S; SILVA, D. P. da. A influência da estrutura escolar no processo de ensino-aprendizagem: uma análise baseada nas experiências do estágio supervisionado em Geografia. Geografia Ensino \& Pesquisa, v. 19, n. 3, set.-dez. 2015. Disponível em: https://periodicos.ufsm.br/geografia/article/ viewFile/14315/pdf Acesso em: 12 jun. 2020.

NÓVOA, A. (org.). Os professores em formação. Lisboa, Portugal: Dom Quixote, 1997.

NÓVOA, A. Os professores e as histórias de vida. In: NÓVOA, António. Vidas de professores. 2. ed. Porto: Porto Editora, 2013.

ROCHA, L.D. Avaliação do curso de Licenciatura em ciências biológicas da Unifal-MG na perspectiva de seus egressos. Revista Profissão Docente, v. 13, n. 28, p. 76-98, 2013.

SCHÖN, D.A. Educando o Profissional Reflexivo: um novo design para o ensino e a aprendizagem. Porto Alegre: Artmed, 2000.

SELLES, S.E.; FERREIRA, M.S. O professor de Ciências e o movimento renovador dos anos 1950/70. In: CONGRESSO LUSO-BRASILEIRO DE HISTÓRIA DA EDUCAÇÃO. 7., Porto. Anais. Porto: Universidade do Minho, 2008. p.1-12

TARDIF, M. Saberes docentes e formação profissional. 13 ed. Petrópolis, RJ: 2012

TOMITA, N.Y. De História Natural a Ciências Biológicas. Ciência e Cultura, v. 47, n.12, p. 1173-1177, dez. 1990.

UFPA. Projeto Pedagógico do Curso de Licenciatura em Ciências Biológicas. Belém: UFPA/ICB, 2019. Disponível em: http://icb.ufpa.br/cursos/pagina. 
php?p=1\&tipo=1 Acessado em 20 mar 2020.

VASCONCELOS, S. D.; LIMA, K. E. C. O professor de Biologia em formação: reflexão com base no perfil socioeconômico e perspectivas de licenciandos de uma universidade pública. Ciênc. educ. (Bauru) [online]. 2010, vol.16, n.2, pp.323-340. Disponível em: < http://dx.doi.org/10.1590/s151673132010000200004>. Acessado em 05 mai 2020.

VYGOTSKI, L. S. A formação social da mente. São Paulo: Martins Fontes, 1999.

Data de recebimento: 22.07 .2020

Data de aceite: 23.12 .2020 